\title{
Linking like with like: optimising connectivity between environmentally-similar habitats
}

\author{
Diogo Alagador - Maria Triviño • \\ Jorge Orestes Cerdeira • Raul Brás • \\ Mar Cabeza $\cdot$ Miguel Bastos Araújo
}

Received: 5 April 2011/Accepted: 1 January 2012/Published online: 10 January 2012

(C) Springer Science+Business Media B.V. 2012

\begin{abstract}
Habitat fragmentation is one of the greatest threats to biodiversity. To minimise the effect of fragmentation on biodiversity, connectivity between otherwise isolated habitats should be promoted. However, the identification of linkages favouring connectivity is not trivial. Firstly, they compete with other land uses, so they need to be cost-efficient. Secondly, linkages for one species might be barriers for others, so
\end{abstract}

Electronic supplementary material The online version of this article (doi:10.1007/s10980-012-9704-9) contains supplementary material, which is available to authorized users.

D. Alagador $(\bowtie) \cdot$ M. Triviño $\cdot$ M. Cabeza

M. B. Araújo

Department of Biodiversity and Evolutionary Biology, Museo Nacional de Ciencias Naturales, CSIC, C/José

Gutiérrez Abascal, 2, 28006 Madrid, Spain

e-mail: diogo.alagador@gmail.com

D. Alagador · J. O. Cerdeira

Forest Research Centre, Instituto Superior de Agronomia,

Technical University of Lisbon (TULisbon),

Tapada da Ajuda, 1349-017 Lisbon, Portugal

\section{J. O. Cerdeira}

Group of Mathematics, Department of Biosystems'

Sciences and Engineering, Instituto Superior de

Agronomia, Technical University of Lisbon (TULisbon),

Tapada da Ajuda, 1349-017 Lisbon, Portugal

R. Brás

Instituto Superior de Economia e Gestão, Technical

University of Lisbon, Rua do Quelhas 6, 1200-781

Lisbon, Portugal they should effectively account for distinct mobility requirements. Thirdly, detailed information on the auto-ecology of most of the species is lacking, so linkages need being defined based on surrogates. In order to address these challenges we develop a framework that (a) identifies environmentally-similar habitats; (b) identifies environmental barriers (i.e., regions with a very distinct environment from the areas to be linked), and; (c) determines cost-efficient linkages between environmentally-similar habitats, free from environmental barriers. The assumption is that species with similar ecological requirements occupy

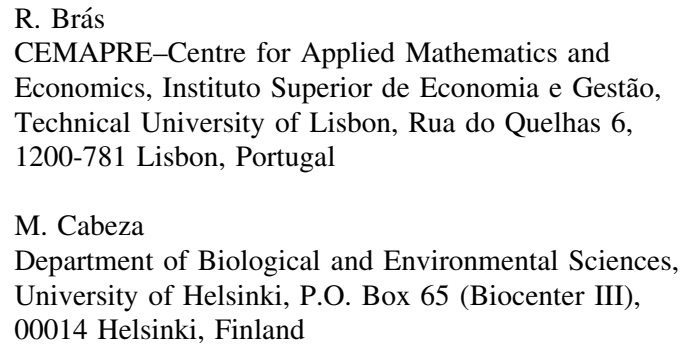

M. B. Araújo

Rui Nabeiro Biodiversity Chair, CIBIO,

University of Évora, Largo dos Colegiais,

7000 Évora, Portugal 
the same environments, so environmental similarity provides a rationale for the identification of the areas that need to be linked. A variant of the classical minimum Steiner tree problem in graphs is used to address c). We present a heuristic for this problem that is capable of handling large datasets. To illustrate the framework we identify linkages between environmentally-similar protected areas in the Iberian Peninsula. The Natura 2000 network is used as a positive 'attractor' of links while the human footprint is used as 'repellent' of links. We compare the outcomes of our approach with cost-efficient networks linking protected areas that disregard the effect of environmental barriers. As expected, the latter achieved a smaller area covered with linkages, but with barriers that can significantly reduce the permeability of the landscape for the dispersal of some species.

\section{Keywords Connectivity - Environmental}

surrogates · Graph theory - Iberian Peninsula · Minimum Steiner tree problem · Protected areas . Spatial conservation planning

\section{Introduction}

Habitat fragmentation ranks among the highest threats to global biodiversity (Butchart et al. 2010; IUCN 2010) and this threat is likely to be exacerbated with climate change (Hannah et al. 2007; Araújo et al. 2011a). To minimise this threat, landscape connectivity should be enhanced with the identification and protection of linkages between areas of high conservation value (Fahrig and Merriam 1994; Hanski 1999). The underlying idea is that connectivity facilitates species dispersal, thus the rescue of small populations from local extinction (due to demographic or environmental stochasticity), while favouring the recolonization of suitable habitats (Bull et al. 2007). A major challenge in conservation and landscape ecology is to develop automated procedures that effectively identify linkages for multitude of species of conservation concern (Beier et al. 2011).

Several approaches have been developed to identify linkages between natural areas. These approaches are usually derived from two different bodies of literature: reserve design and corridor design. Reserve design typically involves strategies to achieve maximum representation of species in reserves given sets of constraints. Such constraints are often derived from the Island Biogeography and Metapopulation theories and seek to achieve a spatial reserve configuration that maximises species persistence (for a review see, Araújo 2009). Mathematical programming techniques have been proposed to address species persistence in reserve design. The techniques included rules to achieve contiguous reserve systems (e.g., Williams 2002; Cerdeira et al. 2005; Önal and Briers 2005; Önal and Wang 2008; Wu et al. 2011), contiguous areas of distribution for the focal species (e.g., Cerdeira et al. 2010), or approaches where spatial criteria are incorporated in the objective function to be optimised (for a review see, Williams et al. 2005). Criteria include compactness (e.g., Williams and ReVelle 1998; Rothley 1999; McDonnell et al. 2002; Fischer and Church 2003; Önal and Briers 2003), diameter (e.g., Önal and Briers 2002) and proximity between pairs of reserves (e.g., Önal and Briers 2002; Alagador and Cerdeira 2007).

Corridor design seeks to optimally link habitats where species of conservation interest occur. The primary input for corridor design is a permeability surface representing the cost of moving across landscape units (Taylor et al. 1993). Ideally, movement costs should be tuned for individual species, but since information is usually lacking for large numbers of species, multi-species corridor design focuses on general measures of landscape permeability (Chetkiewicz and Boyce 2009).

Graph theory provides an appropriate framework for corridor design (Urban and Keitt 2001; Calabrese and Fagan 2004). If one assumes that each landscape unit is a node in a graph (with an associated permeability measure) and edges between pairs of nodes represent the ability of a species to directly move between the corresponding landscape units, then the most efficient way to link a set of particular nodes (called terminals) is readily-expressed by a classical optimisation problem, called minimum Steiner tree (MST) problem in graphs (Du and Hu 2008). MST was introduced in the context of spatial conservation planning by Sessions (1992), who discussed the limitations of algorithms to find optimal MST solutions for real conservation problems, which are characterized by vast amount of data. Subsequently, Williams (1998) and Conrad et al. (2010) worked on extensions of the MST problem to obtain solutions 
where linkage costs are balanced with suitability of the selected linkages. Recently, an open-access software package (LQGraph) was released to implement MST for corridor design (Fuller et al. 2006; Fuller and Sarkar 2006).

The identification of efficient linkages when several types of terminal nodes (i.e. habitat units) exist, and nodes for linking these different types may not coincide, is a new variant of the MST problem. In this work, we address this problem as a major step of a framework to effectively promote connectivity for multiple species. The framework consists of: (a) identification of environmentally-similar habitats (expected to accommodate groups of species with similar environmental requirements); (b) identification of environmental barriers (i.e., regions with a very distinct environment from the environmentally-similar areas to be linked), and; (c) selection of costefficient linkages between environmentally-similar habitats, free from environmental barriers (i.e., not including regions environmentally distinct from the habitats to be linked). We handle (a) and (b) using cluster analysis and we tackle c) using a heuristic that treats the problem as a sequence of MST problems.

We illustrate the framework using the Iberian Peninsula protected areas as the habitat units to be linked. We use climatic variables to assign protected areas into classes (under the assumption that climatically-similar areas hold similar pools of species) and to characterise landscape permeability for each species pool. Linkages between environmentally similar protected areas were favourably established across Natura 2000 areas (European Community Directive 92/43/EEC) because these are already under some form of protection. In contrast, areas highly modified by human activities, i.e., with high human footprint (Sanderson et al. 2002), were excluded from candidate linkages as they are unlikely suitable for species dispersal. The outcomes of our approach for selecting linkages between protected areas are compared with networks selected using an identical approach but ignoring climatic information.

\section{Methods}

The framework is exemplified using Iberian Peninsula protected areas as the habitat units (i.e., terminals) to be connected. The Iberian Peninsula map was divided into 580,696 cells following the UTM $1 \mathrm{~km} \times 1 \mathrm{~km}$ grid. The map resolution was chosen to ensure consistency with the resolution of the climatic dataset (see below) and to generate a sufficiently high number of cells to challenge the practicability of the linkage algorithm proposed herein (see below).

Protected areas data were obtained from the Portuguese and Spanish Environmental Ministries and included 681 areas encompassing a wide range of national and international conservation conventions and cells with some amount of protected areas were treated as terminal nodes for analysis $(80,871$ cells, approx. 14\% of the cells in the Iberian Peninsula) (Fig. S1.1 in the Supplementary material). Natura 2000 areas not overlapping with protected areas were not considered as terminal nodes.

The Natura 2000 network (European Community Directive 92/43/EEC) is a European-scale conservation scheme designed to complement nationallydefined protected areas. It is widely present across the European landscape and therefore has potential to be used for connectivity purposes (Saura and PascualHortal 2007). We used Natura 2000 point/polygon data (downloaded from http://www.eea.europa.eu/ data-and-maps/data/natura-1) (Fig. S1.1 in the Supplementary material) to calculate the proportion of each cell not covered by Natura 2000 areas. These values were used as linkage-costs $c(s)$, for each cell $s$. We settled $c(s)=0$ for each terminal cell.

We used the human footprint index (Sanderson et al. 2002; downloaded from: http://www.ciesin. columbia.edu/wild_areas/register1.html), at $1 \mathrm{~km} \times 1 \mathrm{~km}$ cell size (Fig. S1.1 in the Supplementary material), as a measure of human modification, $h f(s)$ (Baldwin et al. 2010; Theobald 2010). The human footprint index ranges from 1 (low human impact) to 100 (high human impact). Since a negative relationship between human footprint and permeability of the cells for species' dispersal was assumed, cells with $h f(s)$ over a specified threshold (see below) were not considered as candidates for linkages. We settled $h f(s)=0$ for terminal cells.

Monthly data of four climatic variables (maximum temperature, minimum temperature, total precipitation and standard deviation of the minimum temperature), from 1961 to 1990 , were averaged to characterize current climatic conditions in the Iberian Peninsula (Fig. S1.1 in the Supplementary material). These variables were selected because they are considered 
important drivers of species' distributions at large spatial scales (Hawkins et al. 2003; Whittaker et al. 2007). Climatic data, at $1 \mathrm{~km} \times 1 \mathrm{~km}$, were provided by the Instituto de Meteorologia (Portugal) and the Agencia Estatal de Meteorologia (España) (for a full description of data see, Araújo et al. 2011b).

\section{Environmental classification of protected areas}

We carried out a principal components analysis (PCA) to reduce the dimensionality and the correlative effects of the climatic data. We retained the two PCA components that explained the greatest proportion of the data variability (Fig. S2.1, Tables S2.1 and S2.2 in the Supplementary material). These components were then used to group Iberian protected areas into climatically similar clusters. Specifically, we computed the arithmetic mean of the two PCA components in the centroids of all individual protected areas. These centroids were chosen as units for the cluster analysis. We developed a $k$-means algorithm (Fielding 2007) for grouping protected areas into homogeneous climatic units (i.e., minimizing the summed Euclidean distances of each class-member to its respective classcentroid). The algorithm is a simulated annealing approach (Aarts et al. 1997), which, at each iteration, randomly selects a protected-area centroid and considers the possibility of its allocation in a different class. We used 10,000 iterations for each 50 uniformly selected initial classification-seeds, and saved the best solution. The number of climatic types $(k=4)$ was selected a priori to limit the number of climatic clusters in Iberian Peninsula (i.e., alpine, continental, Mediterranean, and oceanic), in line with the KoppenGeiger climatic classification for the region (Peel et al. 2007) (Table S2.3 in the Supplementary material).

\section{Identification of barriers}

We considered two types of barriers: one defined by the human footprint index and the other defined by climate data. Areas with high human footprint $h f(s)$ values were assumed to be poorly permeable to species' movement. We defined a threshold, $H$, and excluded as candidate areas for linkages between protected areas the cells $s$, for which $h f(s)>H$. We used $H \in\{50,60\}$, as low values of $H$ would retrieve an excessively fragmented landscape (i.e., many landscape barriers) and high values of $H$ resulted in highly disturbed cells being included (Fig. S3.1 and Table S3.1 in the Supplementary material).

In addition to the human footprint barriers we also considered climatic barriers. Here, the centroid of each climatic class in the final cluster was used as an archetype of the climate of that class, and the Euclidean distances, in the climatic space, of each (unprotected and protected) cell to the centroid of each class were computed. This retrieves $k$ values, $d_{i}(s)$, for each cell, expressing the dissimilarity of cell $s$ to every climatic class- $i$.

Since the goal is to link climatically similar protected areas across cells that do not differ significantly from the mean climatic conditions of protected areas, we defined a threshold value $B_{i}$ assuming that cells with $d_{i}(s)>B_{i}$ are climatic barriers, thus not adequate for linking protected areas of class- $i$. We defined $B_{i}$ according to two scenarios. In the first scenario, $B_{i}$ was defined as the largest dissimilarity $d_{i}(s)$, among the protected cells $s$ in every protected area of class- $i\left[\max d_{i}(s)\right]$. In the second and more restrictive scenario, the barriers for class- $i$ were established as the top $25 \% d_{i}(s)$ values for cells $s$ not belonging to $i$, i.e., $\left[Q_{3} d_{i}(s)\right]$ (Table $\mathrm{S} 4.1$ in the Supplementary material).

The linkage algorithm

Linking protected areas within each class- $i$, with minimum cost and with no environmental barriers for class- $i$, is a generalization of the (node weighted) MST problem in graphs, where protected areas act as terminal nodes. The MST is the special case when only one class exists. The MST is a difficult problem, and heuristics are the only option to handle even moderate size instances (say a few hundred of nodes and a few dozens of terminals). A simple heuristic for the MST problem is what is called the minimum spanning tree approach (see Du and Hu 2008). First, minimum cost paths ( $\min$ cost paths: Dijkstra 1959) are computed between every pair of terminals. Next, these min cost paths are used to weight the edges of a complete graph whose nodes are terminals, and the minimum spanning tree for this graph (Kruskal 1956; Prim 1957) is obtained. Finally, the union of paths, corresponding to the edges of the minimum spanning tree, is pruned from redundant nodes (i.e., nodes that are not necessary to link all terminals of each class). The pruning 
process ends when the solution is minimal, i.e., every node is needed for linkage.

We extended this approach when there are $k>1$ classes. For each of the $k$ ! permutations of the $k$ climatic classes, we applied the above MST procedure to link protected areas of the class appearing first on the permutation. We then assigned "cost zero" to every cell of that linkage, and proceed as above to link the protected areas belonging to the second class of the permutation. This was repeated for the third, fourth,... and $k$ classes. At the end, the solution consisting of the union the $k$ linkages was turned minimal. The final climate network was the minimum cost network among the $k$ ! networks considered (see a schematic diagram of the algorithm in Fig. 1).

In our implementation, special concern was given to data structures to allow the heuristic to run large instances, such as the Iberian Peninsula example.

It should be noted that, depending on the specific parameterization of climatic barriers $\left(B_{i}\right)$ and the

1) Define general landscape barriers $(H)$ using:

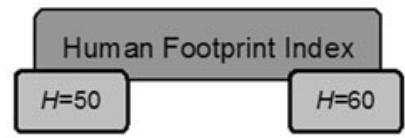

2) Choose a permutation of $P^{*}$ classes,

3) Define specific barriers for class $i\left(B_{i}\right)$, using:

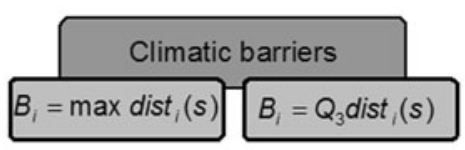

4) Link $\mathrm{PA}^{*}$ of class $i$, minimising:

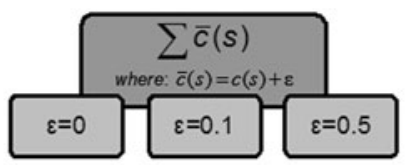

5) Add the linking cells to the current solution, for these cells update:

$\bar{c}(s)=0$

7) Turn the solution minimal,

9) Select the best solution.

${ }^{\star}$ Protected areas

Fig. 1 Simplified overview of the procedures implemented in the connectivity algorithm human footprint threshold $(H)$, pairs of protected areas of the same class might not be linked in the final solution. This can happen when all paths connecting two protected areas belonging to some class- $i$ include some cell, $s$, with $d_{i}(s)>B_{i}$ or $h f(s)>H$. In other words, for some climatic classes, the resulting climate network can have more than one connected component (Fig. 2a). A connected component of class- $i$ is a maximal (with respect to inclusion) subset of (protected and unprotected) cells connecting protected areas of class- $i$ that are not barriers for that class. This generalizes the notion of a connected component in a graph (e.g., Rayfield et al. 2011).

Our algorithm generates a climate network with the minimum number of connected components for each class. We used the number of components (which strictly depends on the values used for $B_{i}$ and $H$ ) as an indicator of linkage effectiveness. A large number of components for a given class reflect a highly fragmented network. This may indicate an ineffective linkage for that class.

We also considered balancing the cost of the final solution with the number of selected cells using an area-penalty. For every cell, $s$, we added a positive fixed term $\varepsilon$ to the cost, $c(s)$, obtaining the modified cost $\bar{c}(s)=c(s)+\varepsilon$. Larger $\varepsilon$ values determine fewer cells in the solution (Fig. 2b). We tested three different values $(\varepsilon=0 ; \varepsilon=0.1$ and $\varepsilon=0.5)$.

\section{Comparing network effectiveness}

We compared the climate networks with linkages obtained without use of climatic information, i.e., using the procedure described above, but assuming that all protected areas belong to the same climatic class and that no climatic barriers exists. We denote these networks as simple networks.

We obtained climate networks and simple networks for each of the 12 parameterizations above described ( 2 human footprint thresholds $\times 2$ climatic barriers assumptions $\times 3$ area-penalty values). We compared solutions in terms of efficiency (i.e., total surface area and total cost) and effectiveness. To assess effectiveness of simple networks we recovered the protected areas climatic classification and for each climatic class- $i$ we removed the barriers for that class. Then, we counted the number of connected components of class- $i$, which we compared with the number of 


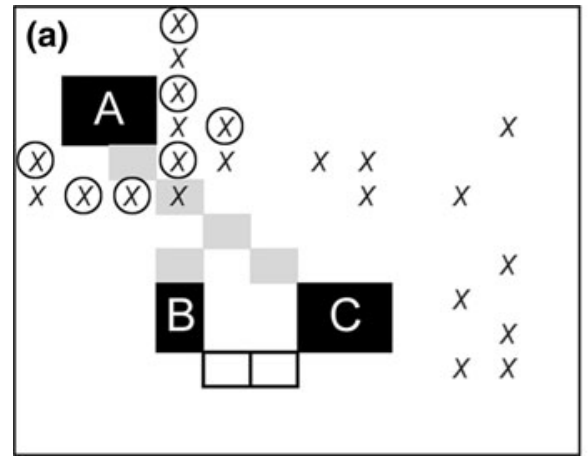

Fig. 2 The effect of changing parameters over the linkage solutions, using a synthetic example where three habitat units $(A, B$ and $C$ ) are to be linked. a The barrier effect (landscape and environmental barriers). When barriers (circles) do not isolate sets of habitats the grey cells are a likely solution to connect $A, B$ and $C$. Otherwise, when barriers (crossed-cells) isolate sets of habitats, a linkage is only required to connect $B$ and $C$ (thick-

connected components in the corresponding climate network.

\section{Results}

Outputs from the two types of networks (climate and simple networks) obtained under different parameterizations $\left(\varepsilon \times H \times B_{i}\right)$ showed marked variability on the extent (Table 1), effectiveness (Fig. 3) and spatial location (Fig. 4, and Table S5.1 in the Supplementary material) of linkages connecting the Iberian protected areas. While climate networks ranged from 5,328 to $6,666 \mathrm{~km}^{2}$, simple networks varied from 4,873 to $6,373 \mathrm{~km}^{2}$. This means that climate networks required $3.2-14.4 \%$ more area than simple networks, and also identified more linkages outside the Natura 2000 network (3.8-19.2\% more area). Models penalizing the number of cells and the total area in the solution $(\varepsilon=0.5)$ retrieved more distinct solutions between the approaches; a trend that is true for both $H=50$ and $H=60$ scenarios (Table 1).

As expected, climate networks performed better in terms of avoiding climatic barriers than equivalent simple networks. In fact, by identifying and bypassing climatic barriers, climate networks included $6.0-35.2 \%$ less protected area components than simple networks, a fact that is contingent on the spatial pattern of unsuitable areas provided by $H$ and $B_{i}$. Differences in the number of components vary with the climatic classes, because linkages between

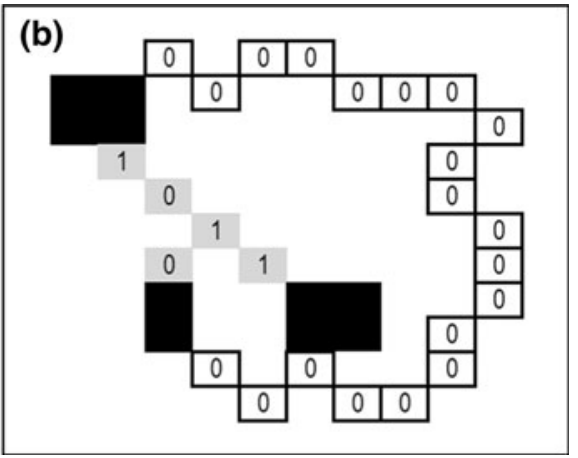

bordered white cells), while $A$ stays isolated; $\mathbf{b}$ The effect of the area-penalty value, epsilon $(\varepsilon)$. When $\varepsilon<0.2$, the "cheapest" connection is the one passing through the 20 thick-bordered zero-cost white cells (total cost $=20 \times \varepsilon$ ). When $\varepsilon>0.2$, the cheapest connection is the one passing through the grey cells with zero and one-costs (solution cost $=3 \times(1+\varepsilon)+2 \times \varepsilon)$

protected areas in particular classes are more challenged by barriers.

When barriers included the $25 \%$ more dissimilar cells outside protected areas of each type $\left[B_{i}>Q_{3}\right.$ $d_{i}(s)$ ], greater differences between the climate and simple networks were obtained for the alpine protected area network (Table 1). With climate networks, linkages for these protected areas retrieved few components (2-3) being 72.7-86.7\% more effective at guaranteeing connectivity than linkages in the simple networks. Turning $H=50$ to $H=60$ greatly affected comparisons of both approaches for the continental protected areas, as effectiveness gains with climate networks varied approximately from 30 to $60 \%$. This means that the general (landscape) barriers are the major determinant of fragmentation for these protected areas. Differences between approaches were less marked when connecting Mediterranean and oceanic protected areas, with gains in effectiveness being approximately $15 \%$ for climate networks. Using $H=50$, effectiveness gains in oceanic protected areas were narrower (3.0-5.9\%).

Comparing efficiency and effectiveness of climate and simple networks enables the assessment of the extent to which a fixed budget produces solutions performing differently in terms of realized linkage achievements. Climate networks are inevitably more costly than simple networks when the same parameterization is used. Therefore, we manipulated areapenalty to obtain climate and simple networks with similar costs. For example, analysing the more 


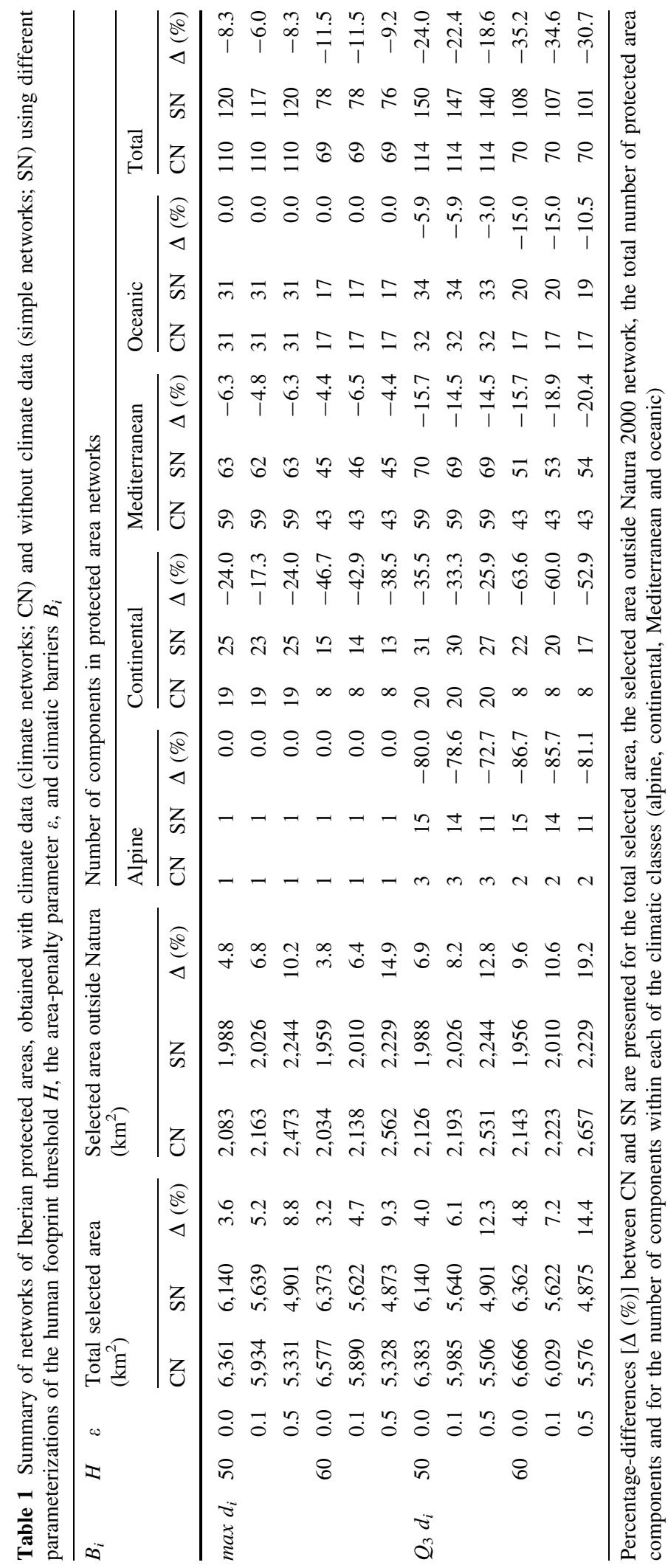




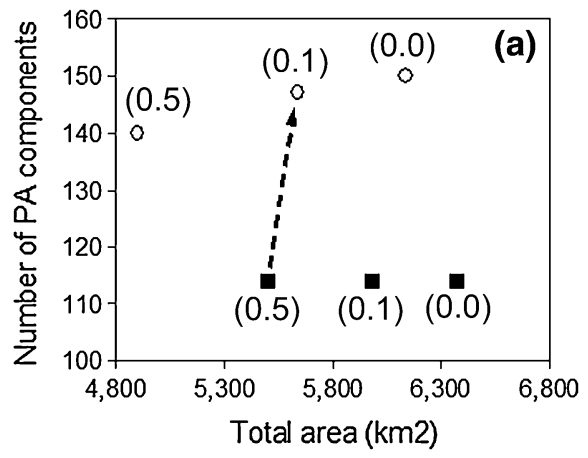

Fig. 3 Comparison of networks delineated with climate data (climate networks $C N$ ) (filled squares) with simple networks without climatic data (simple networks $S N$ ) (open circles) in terms of efficiency: a Total area selected, b Total area selected not listed in Natura 2000; and effectiveness (number

(a) $\mathrm{CN}$

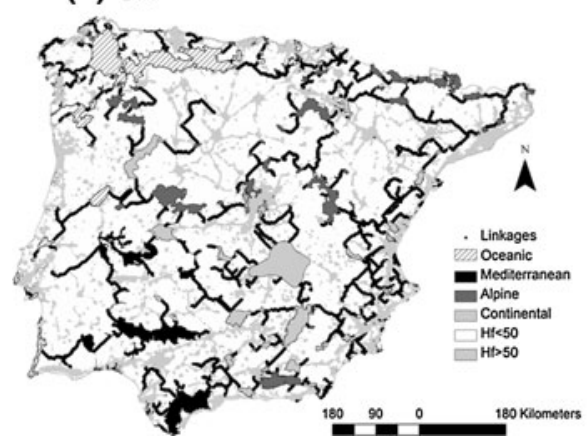

Fig. 4 Maps of linkages for the Iberian Peninsula protected areas obtained with climate data (climate networks $C N$ ), using an area-penalty $\varepsilon=0.1$ and climatic barriers $B_{i}>Q_{3} d_{i}(s)$, and without climate data (simple networks $S N$ ) using an area-penalty $\varepsilon=0.5$. Both networks are delineated over a similar amount of

conservative scenario (i.e., with more barriers) $\left[H=50, B_{i}>Q_{3} d_{i}(s)\right]$, the climate networks requiring less surface area targeted $5,506 \mathrm{~km}^{2}$, encompassing 114 protected area components, while a similar-size simple networks $\left(5,640 \mathrm{~km}^{2}\right)$ contained 147 protected area components (Fig. 3a). An equivalent loss of linkage effectiveness for the simple networks occurred when the selected area outside Natura 2000 was used as a measure of efficiency (Fig. 3b). In this case the most-costly simple network $\left(2,244 \mathrm{~km}^{2}\right)$ presented more $22.8 \%$ protected areas components than the climate network using a similar amount of area outside Natura $2000\left(2,193 \mathrm{~km}^{2}\right)$. These differences are directly translated to the spatial patterns obtained for both network types (Fig. 4).

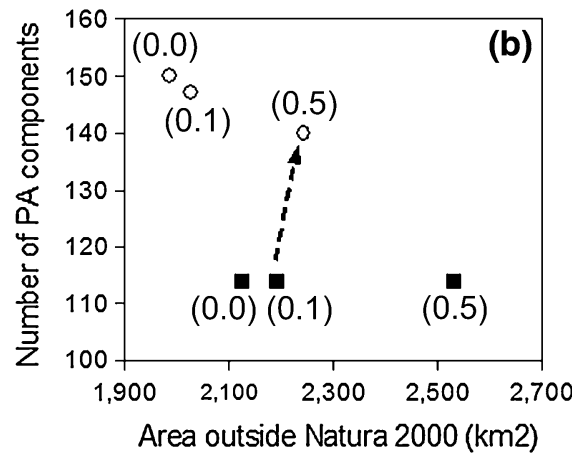

components in protected area networks), for the most conservative scenario under consideration $\left[H=50, B_{i}>Q_{3} d_{i}(s)\right]$, using distinct area-penalty parameterizations ( $\varepsilon$ values in parenthesis). Arrows represent comparisons of pairs of networks sharing similar costs

(b) $\mathrm{SN}$

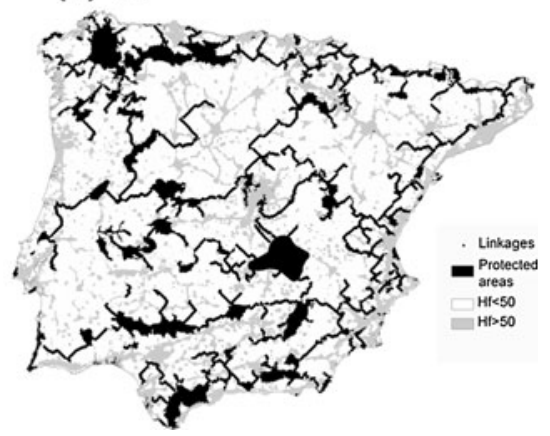

land not listed within Natura 2000 (see Table 1). Landscape barriers (light grey areas) are defined after applying a threshold value $(H=50)$ to filter out the areas with the highest human footprint values

\section{Discussion}

We have shown that extending the MST to account for different types of terminal habitats provides a useful framework for identifying linkages between natural areas using environmental data. The framework is based on the assumption that the environment drives, at least partially, species' distributions, so that habitats with similar environments are likely to share similar assemblages of species or act as potential 'sources' and 'sinks' for species' dispersal. It follows from this assumption that linkages between protected areas should preferentially be established between environmentally-similar areas. Although this assumption is problematic for the selection of complementary sets of 
areas in reserve selection (see, Araújo et al. 2001; Araújo et al. 2004; Hortal et al. 2009), it is reasonable to expect that when species occupying a given environment are, for whatever reason, forced to move elsewhere, they preferentially move to similar environments (Chetkiewicz et al. 2006; Sawyer et al. 2011). The choice of the relevant environmental attributes to be used should be concerted with the autoecology of focal species and the scale of analysis (i.e., extent and resolution of the study area). For example, we used climate to obtain a broad characterization of species' permeability in Iberian Peninsula as it is seen highly correlated with plant and animal species' distributions at such spatial extent and grain size (Hawkins et al. 2003; Whittaker et al. 2007). Several other environmental variables could be used instead (e.g., vegetation types, topography, geology, biogeography, phylogeny and disturbance data, or different combinations of them).

Two problems may arise when using climatic variables in our framework in a context of climate change. First, sets of climatically-similar habitats are likely to be shuffled with climate change and therefore an habitat unit A initially targeted to be linked with a similar unit B, may no longer need such linking, but requires a linkage with a new similar unit $\mathrm{C}$. Second, areas identified as linkages for a given habitat class may lose climatic suitability for that class. In an extreme scenario, they may even turn into barriers to species' movements. To develop conservation maps robust to climate change (without relying on projected emissions of greenhouse gases, air-ocean circulation models, and climate-envelope models), several studies support the use of more steady factors driving biodiversity patterns and processes, like topographic and geomorphologic variation (Anderson and Ferree 2010; Beier and Brost 2010; Game et al. 2011).

Our framework is flexible enough to accommodate simple conservation purposes. For example, natural habitats may be so heavily fragmented that no continuous swaths of land are left to be conserved. Furthermore, there are species able to cross some amount of inhospitable land. In cases such as these, linking habitats with stepping-stones may open opportunities for effective and less-conflicting conservation measures, because stepping stones require lesser area than continuous linkages. Our framework may be easily adapted to delineate stepping-stones optimally. This can be accomplished by using adjacency rules between cells that integrate a "functional distance" defined by the distance that the least mobile focal species are able to move across unsuitable habitat. Once a given cell is chosen for linkage at least one other cell, distancing no more than the "functional distance", needs also to be selected.

The cost-optimised networks obtained with our framework only require a unique path between each pair of habitat units of the same class. This may not be the most precautionary option to take (Pinto and Keitt 2009). One can increase network robustness by identifying multiple paths to link habitats of the same class. Our framework is able to reach this by replacing the execution of the last step of the linkage algorithm (i.e., turning the solution minimal), with the removal of only the non-terminal cells that are connected to no more than one other cell. Then, if non-overlapping linkages are desired, the heuristic can be repeatedly run removing all the selected non-terminal cells from the previous solutions. Clearly, this can be executed only for those habitat classes with greater numbers of threatened species or for the classes requiring longer linkages, as these are less likely to be implemented or are more exposed to threats (Beier and Noss 1998). Furthermore, in circumstances where lengthy linkages are not critical to maintain long distance dispersal events, it may be wiser to avoid linking distant habitat units. For example, the analysed region may be subdivided in order to obtain sub-areas with higher densities of habitat units for each habitat class. Independent solutions for each of these sub-areas may be obtained thereafter.

Finally, it is critical to realize that if the main interest of conservation is the persistence of species in fragmented landscapes, the sole integration of species' movement patterns is insufficient. Species' dispersal data should be combined with other factors that determine species' persistence at various spatial and temporal scales. The framework here presented should be considered as part of a broader analysis towards the promotion of such complex and integrative objective as it is allowing species to persist.

Acknowledgments DA was supported by a $\mathrm{PhD}$ studentship (BD/27514/2006) and is now funded by a post-doctoral fellowship (BPD/51512/2011) awarded by the Portuguese Foundation for Science and Technology (FCT); MT is funded by a FPI-MICINN (BES-2007-17311) fellowship; MC was funded through a Spanish RyC fellowship; JOC is partially supported by FCT through the European Community Fund 
FEDER/POCI 2010 and by the FCT project PTDC/AAC-AMB/ $113394 / 2009$; MBA is currently funded by the ECOCHANGE project and acknowledges support from the Rui Nabeiro/Delta Chair in Biodiversity and the Spanish Research Council (CSIC). We are grateful to Evgeniy Meyke for the treatment of Iberian Peninsula Natura 2000 data.

\section{References}

Aarts EHL, Korst JHM, van Laarhoven PJM (1997) Simulated annealing. In: Aarts E, Lenstra JK (eds) Local search in combinatorial optimization. Wiley, New York, pp 91-120

Alagador D, Cerdeira JO (2007) Designing spatially-explicit reserve networks in the presence of mandatory sites. Biol Conserv 137:254-262

Anderson MG, Ferree CE (2010) Conserving the stage: climate change and the geophysical underpinnings of species diversity. PLoS ONE 5:e11554

Araújo M (2009) Climate change and spatial conservation planning. In: Moilanen A, Possingham H, Wilson KA (eds) Spatial conservation prioritization: quantitative methods and computational tools, Oxford University Press, Oxford, pp 172-184

Araújo MB, Humphries CJ, Densham PJ, Lampinen R, Hagemeijer WJM, Mitchell-Jones AJ, Gasc JP (2001) Would environmental diversity be a good surrogate for species diversity? Ecography 24:103-110

Araújo MB, Densham PJ, Williams PH (2004) Representing species in reserves from patterns of assemblage diversity. J Biogeogr 31:1037-1050

Araújo MB, Alagador D, Cabeza M, Nogués-Bravo D, Thuiller W (2011a) Climate change threatens European conservation areas. Ecol Lett 14:484-492

Araújo MB, Guilhaumon F, Neto DR, Pozo I, Calmaestra RG (2011b) Impactos, vulnerabilidad y adaptación al cambio climático de la biodiversidad española, 2nd edn. Fauna de Vertebrados, Madrid

Baldwin RF, Perkl R, Trombulak S, Burwell W (2010) Modeling ecoregional connectivity. In: Trombulak S, Baldwin RF (eds) Landscape-scale conservation planning. SpringerVerlag, Dordretch

Beier P, Brost B (2010) Use of land facets to plan for climate change: conserving the arenas, not the actors. Conserv Biol 24(3):701-710

Beier P, Noss R (1998) Do habitat corridors provide connectivity? Conserv Biol 12:1241-1252

Beier P, Spencer W, Baldwin RF, McRae BH (2011) Toward best practices for developing regional connectivity maps. Conserv Biol 25:879-892

Bull JC, Pickup NJ, Pickett B, Hassell MP, Bonsall MB (2007) Metapopulation extinction risk is increased by environmental stochasticity and assemblage complexity. Proc R Soc B Biol Sci 274:87-96

Butchart SHM, Walpole M, Collen B, van Strien A, Scharlemann JPW, Almond REA, Baillie JEM, Bomhard B, Brown C, Bruno J, Carpenter KE, Carr GM, Chanson J, Chenery AM, Csirke J, Davidson NC, Dentener F, Foster M, Galli A, Galloway JN, Genovesi P, Gregory RD,
Hockings M, Kapos V, Lamarque J-F, Leverington F, Loh J, McGeoch MA, McRae L, Minasyan A, Morcillo MH, Oldfield TEE, Pauly D, Quader S, Revenga C, Sauer JR, Skolnik B, Spear D, Stanwell-Smith D, Stuart SN, Symes A, Tierney M, Tyrrell TD, Vié J-C, Watson R (2010) Global biodiversity: indicators of recent declines. Science 328:1164-1168

Calabrese JM, Fagan WF (2004) A comparison-shopper's guide to connectivity metrics. Front Ecol Environ 2:529-536

Cerdeira JO, Gaston KJ, Pinto LS (2005) Connectivity in priority area selection for conservation. Environ Model Assess 10:183-192

Cerdeira JO, Pinto LS, Cabeza M, Gaston KJ (2010) Species specific connectivity in reserve-network design using graphs. Biol Conserv 143:408-415

Chetkiewicz CLB, Boyce MS (2009) Use of resource selection functions to identify conservation corridors. J Appl Ecol 46:1036-1047

Chetkiewicz C-LB, St. Clair CC, Boyce M (2006) Corridors for conservation: integrating pattern and process. Annu Rev Ecol Evol Syst 37:317-342

Conrad J, Gomes CP, van Hoeve W-J, Sabharwal A, Suter JF (2010) Incorporating economic and ecological information into the optimal design of wildlife corridors, Cornell University, Ithaca

Dijkstra EW (1959) A note on two problems in connexion with graphs. Numer Math 1:269-271

Du D, Hu X (2008) Steiner tree problems in computer communication networks, World Scientific Publishing Co Pte Ltd., Singapore

Fahrig L, Merriam G (1994) Conservation of fragmented populations. Conserv Biol 8:50-59

Fielding AH (2007) Cluster and classification techniques for the biosciences. Cambridge University Press, Cambridge

Fischer DT, Church RL (2003) Clustering and compactness in reserve site selection: an extension of the biodiversity management area selection model. For Sci 49:555-565

Fuller T, Sarkar S (2006) LQGraph: a software package for optimizing connectivity in conservation planning. Environ Model Softw 21:750-755

Fuller T, Munguia M, Mayfield M, Sanchez-Cordero V, Sarkar S (2006) Incorporating connectivity into conservation planning: a multi-criteria case study from central Mexico. Biol Conserv 133:131-143

Game ET, Lipsett-Moore G, Saxon E, Peterson N, Sheppard S (2011) Incorporating climate change adaptation into national conservation assessments. Glob Change Biol 17:3150-3160

Hannah L, Midgley GF, Andelman S, Araújo MB, Hughes G, Martinez-Meyer E, Pearson RG, Williams PH (2007) Protected area needs in a changing climate. Front Ecol Environ 5:131-138

Hanski I (1999) Habitat connectivity, habitat continuity, and metapopulations in dynamic landscapes. Oikos 87:209-219

Hawkins BA, Field R, Cornell HV, Currie DJ, Guégan J-F, Kaufman DM, Kerr JT, Mittelbach GG, Oberdorff T, O'Brien EM, Porter EE, Turner JRG (2003) Energy, water, and broad-scale geographic patterns of species richness. Ecology 84:3105-3117

Hortal J, Araújo MB, Lobo JM (2009) Testing the effectiveness of discrete and continuous environmental diversity as a surrogate for species diversity. Ecol Ind 9:138-149 
IUCN (2010) IUCN red list of threatened species. Version 2010.1 IUCN

Kruskal JB (1956) On the shortest spanning subtree of a graph and the traveling salesman problem. Proc Am Math Soc 7:48-50

McDonnell MD, Possingham HP, Ball IR, Cousins EA (2002) Mathematical methods for spatially cohesive reserve design. Environ Model Assess 7:107-114

Önal H, Briers RA (2002) Incorporating spatial criteria in optimum reserve network selection. Proc R Soc Lond B Biol Sci 269:2437-2441

Önal H, Briers RA (2003) Selection of a minimum-boundary reserve network using integer programming. Proc R Soc Lond B Biol Sci 270:1487-1491

Önal H, Briers RA (2005) Designing a conservation reserve network with minimal fragmentation: a linear integer programming approach. Environ Model Assess 10:193-202

Önal H, Wang Y (2008) A graph theory approach for designing conservation reserve networks with minimal fragmentation. Networks 51:142-152

Peel MC, Finlayson BL, McMahon TA (2007) Updated world map of the Köppen-Geiger climate classification. Hydrol Earth Syst Sci 11:1633-1644

Pinto N, Keitt T (2009) Beyond the least-cost path: evaluating corridor redundancy using a graph-theoretic approach. Landscape Ecol 24:253-266

Prim RC (1957) Shortest connection networks and some generalizations. Bell Syst Tech J 36:1389-1401

Rayfield B, Fortin M-J, Fall A (2011) Connectivity for conservation: a framework to classify network measures. Ecology 92:847-858

Rothley KD (1999) Designing bioreserve networks to satisfy multiple, conflicting demands. Ecol Appl 9:741-750

Sanderson EW, Jaiteh M, Levy MA, Redford KH, Wannebo AV, Woolmer G (2002) The human footprint and the last of the wild. Bioscience 52:891-904
Saura S, Pascual-Hortal L (2007) A new habitat availability index to integrate connectivity in landscape conservation planning: comparison with existing indices and application to a case study. Landsc Urban Plan 83:91-103

Sawyer SC, Epps CW, Brashares JS (2011) Placing linkages among fragmented habitats: do least-cost models reflect how animals use landscapes? J Appl Ecol 48:668-678

Sessions J (1992) Solving for habitat connections as a Steiner network problem. For Sci 38:203-207

Taylor PD, Fahrig L, Henein K, Merriam G (1993) Connectivity is a vital element of landscape structure. Oikos 68:571-573

Theobald D (2010) Estimating natural landscape changes from 1992 to 2030 in the conterminous US. Landscape Ecol 25:999-1011

Urban D, Keitt T (2001) Landscape connectivity: a graph-theoretic perspective. Ecology 82:1205-1218

Whittaker RJ, Nogués-Bravo D, Araújo MB (2007) Geographical gradients of species richness: a test of the water-energy conjecture of Hawkins et al. (2003) using European data for five taxa. Glob Ecol Biogeogr 16:76-89

Williams JC (1998) Delineating protected wildlife corridors with multi-objective programming. Environ Model Assess 3:77-86

Williams JC (2002) A zero-one programming model for contiguous land acquisition. Geogr Anal 34:330-349

Williams JC, ReVelle CS (1998) Reserve assemblage of critical areas: a zero-one programming approach. Eur J Oper Res 104:497-509

Williams J, ReVelle C, Levin S (2005) Spatial attributes and reserve design models: a review. Environ Model Assess 10:163-181

Wu X, Murray A, Xiao N (2011) A multiobjective evolutionary algorithm for optimizing spatial contiguity in reserve network design. Landscape Ecol 26:425-437 